\title{
Extending Faculty Development through a Sustainable Community of Prac- tice
}

\section{Sarah Hoyt, Arizona State University}

Sarah Hoyt is currently the Education Project Manager for the NSF-funded JTFD Engineering faculty development program. Her educational background includes two Master's degrees from Grand Canyon University in Curriculum and Instruction and Education Administration. Her areas of interest are in student inclusion programs and creating faculty development that ultimately boost engagement and performance in students from lower SES backgrounds. Prior to her role as project manager, Sarah worked as the SEI Coordinator for a local high school and has also developed an inclusion program for Migrant and Immigrant students that utilized co-teaching and active learning as keystones of the program. She began her educational career as a high school teacher, teaching courses in English, math, and science.

\section{Dr. Lindy Hamilton Mayled, Arizona State University}

Lindy Hamilton Mayled is the Director of Instructional Effectiveness for the Fulton Schools of Engineering at Arizona State University. She has a PhD in Psychology of Learning, Education, and Technology and her research and areas of interest are in improving educational outcomes for STEM students through the integration of active learning and technology-enabled frequent feedback.

\section{Prof. Stephen J Krause, Arizona State University}

Stephen Krause is professor in the Materials Science Program in the Fulton School of Engineering at Arizona State University. He teaches in the areas of introductory materials engineering, polymers and composites, and capstone design. His research interests include faculty development and evaluating conceptual knowledge and strategies to promote conceptual change. He has co-developed a Materials Concept Inventory and a Chemistry Concept Inventory for assessing conceptual knowledge and change for materials science and chemistry classes. He is currently conducting research in two areas. One is studying how strategies of engagement and feedback and internet tool use affect conceptual change and impact on students' attitude, achievement, and persistence. The other is on a large-scale NSF faculty development program and its effect on change in faculty teaching beliefs, engagement strategies, and classroom practice. Recent honors include coauthoring the ASEE Best Paper Award in the Journal of Engineering Education in 2013 and the ASEE Mike Ashby Outstanding Materials Educator Award in 2018.

\section{Prof. Keith D. Hjelmstad, Arizona State University}

Keith D. Hjelmstad is President's Professor of Civil Engineering in the School of Sustainable Engineering and the Built Environment at Arizona State University.

\section{Kara L. Hjelmstad, Arizona State University}

Kara Hjelmstad has been a faculty associate and student teacher supervisor for Mary Lou Fulton Teachers College at Arizona State University since 2010. Previously, she earned an M.Ed. degree in curriculum and instruction, and spent twelve years teaching at the elementary level.

From the fall of 2016 through the spring of 2019, Kara worked with the JTFD Project, an NSF grant working to improve active learning in engineering education. She has completed 300 RTOP classroom observations in ASU engineering courses (civil, environmental, construction, chemical, aero/mechanical, materials, transportation, and biomedical engineering). The RTOP or Reformed Teaching Observation Protocol, is a rubric designed to assess student centered instruction in math and science. Kara also provided instructional coaching for 37 engineering faculty grant participants, after their teaching observations.

\section{Dr. Claire Fletcher Honeycutt, Arizona State University \\ Dr. Eugene Judson, Arizona State University}


Eugene Judson is an Associate Professor of for the Mary Lou Fulton Teachers College at Arizona State University. He also serves as an Extension Services Consultant for the National Center for Women and Information Technology (NCWIT). His past experiences include having been a middle school science teacher, Director of Academic and Instructional Support for the Arizona Department of Education, a research scientist for the Center for Research on Education in Science, Mathematics, Engineering and Technology (CRESMET), and an evaluator for several NSF projects. His first research strand concentrates on the relationship between educational policy and STEM education. His second research strand focuses on studying STEM classroom interactions and subsequent effects on student understanding. He is a codeveloper of the Reformed Teaching Observation Protocol (RTOP) and his work has been cited more than 2200 times and he has been published in multiple peer-reviewed journals such as Science Education and the Journal of Research in Science Teaching.

\section{Lydia Ross, Arizona State University}

Dr. Lydia Ross is a clinical assistant professor in the Mary Lou Fulton Teachers College. She also serves as the executive director of the Association for Education Finance \& Policy. She holds a PhD in Educational Policy and Evaluation from Arizona State University. Her research focuses on equity and access and in higher education, with a focus on STEM.

\section{Prof. James A Middleton, Arizona State University}

James A. Middleton is Professor of Mechanical and Aerospace Engineering and Director of the Center for Research on Education in Science, Mathematics, Engineering, and Technology at Arizona State University. For the last three years he also held the Elmhurst Energy Chair in STEM education at the University of Birmingham in the UK. Previously, Dr. Middleton was Associate Dean for Research in the Mary Lou Fulton College of Education at Arizona State University, and Director of the Division of Curriculum and Instruction. He received his Ph.D. in Educational Psychology from the University of Wisconsin-Madison in 1992, where he also served in the National Center for Research on Mathematical Sciences Education as a postdoctoral scholar.

\section{Prof. Robert J Culbertson}

Robert J. Culbertson is an Associate Professor of Physics. Currently, he teaches introductory mechanics and electrodynamics for physics majors and a course in musical acoustics, which was specifically designed for elementary education majors. He is director of the ASU Physics Teacher Education Coalition (PhysTEC) Project, which strives to produce more and better high school physics teachers. He is also director of Master of Natural Science degree program, a graduate program designed for in-service science teachers. He works on improving persistence of students in STEM majors, especially under-prepared students and students from under-represented groups.

\section{Ke Liu, Arizona State University}




\title{
Extending Faculty Development through a Sustainable Community of Practice
}

\begin{abstract}
Research has shown that creating communities of practice can help solidify organizational learning. With pedagogical shifts towards engagement-style teaching and active learning, institutions are working to create robust faculty development that will not only provide the necessary support for shifting pedagogical styles, but one that will also sustain what is learned and provide an opportunity for faculty to continue that discussion beyond the end of the professional development series. Communities of Practice (CoPs) provide support for faculty that is collaborative, peer-engaged, structured, and non-evaluative. This evidenced-based practice paper examines the extension of a faculty development program through a sustainable CoP across multiple disciplines in engineering at a large southwestern university. The IUSE NSF-funded grant referenced in this study, entitled Just-in-Time-Teaching with Two Way Formative Feedback for Multiple Disciplines (JTFD), began in the fall of 2015 with the goal of shifting teacher-centered learning to student-centered learning through active learning and formative feedback. Once the workshop series concluded, the grant established ongoing CoPs that have been sustained for the final two years of the grant.
\end{abstract}

The initial program utilized a train-the-trainer model with multi-disciplinary engineering faculty participating in eight bi-weekly workshops and six biweekly CoPs for a year-long faculty development program. The trainers, disciplinary leader pairs (DLPs) who were chosen by the PIs, first completed the eight workshops and six CoPs before moving on to lead their own workshops with faculty from the same discipline the following year. Workshop topics included Bloom's Taxonomy, learning objectives, interactive classes, active and cooperative learning, muddiest points, tech tools, and fostering inclusive learning environments. The subsequent CoPs followed a semi-structured format; in other words, each session had chapter from Felder and Brent's Teaching and Learning STEM: A Practical Guide but also provided opportunities for faculty to discuss the process of implementing active learning into their classes and sharing ideas.

The CoPs were created at the request of faculty participants, who asked for an ongoing forum to continue discussions around engineering education-related topics. In the Fall of 2018, the CoPs broadened in scope to include sessions and topics that faculty deemed important for the year. Themes from this semester included tips on integrating active learning into the classroom and migrating course content to the new LMS. In the Spring of 2019, using faculty feedback, the CoP topics were expanded further and included: 3 Ways to Integrate Active Learning into Your Classroom in 10 Minutes or Less!; Asking the Right Questions: A Discussion of Building Tests to Improve Student Achievement; Psychology-Based Approaches to Improving Student Motivation; 5 Features You're Not Using in Canvas (But Should Be). Based on faculty feedback through the use of surveys, the new topics were found to be of value and attendance remained steady with a slow increase. The Fall 2019 topics include Setting the Tone/Building Relationships on the First Day for the Engaged Class; Do My Students 
Know What I Want Them to Know? Using a Backward Design Approach to Assessment; Getting the Wayward Student Back on Track Using Midterm Formative Feedback and Assessment; Motivating Your Students to Finish Strongly: Ending the Semester Successfully. The preferred method of presentation is active lecture to engage the audience.

\section{Introduction and Background}

There are known challenges to establishing, implementing, and sustaining faculty development programs. Some of these obstacles include scheduling hurdles, content delivery, and post-development sustainability [1]. Many professional development sessions are designed to inadvertently inundate faculty with information on a trending pedagogical topic and then leave them to ruminate the feasibility of implementation with little to no support. Because of these factors, creating faculty development opportunities that embed sustainability components has become necessary in helping faculty implement and build success around new instructional practices. This paper aims to examine the degree to which new pedagogy is sustained by creating a community of practice centered around infusing active learning strategies into the engineering classroom and what characteristics of a CoP need to be present to foster that sustainability.

The backdrop for this paper is the aforementioned, large-scale faculty development program at an engineering college in a large, research-based Southwestern university. The program, funded through the National Science Foundation's (NSF) Improving Science Education (IUSE) initiative, is currently in its final year and has focused on infusing active learning into engineering undergraduate classrooms and providing faculty with evidence-based instructional strategies that would foster a more student-centered classroom. Seven engineering disciplines were represented by the faculty participants: aerospace, biomedical, chemical, civil, construction, materials, and mechanical. This paper explores the ability of continuing Communities of Practice to sustain content disseminated in a faculty development program. We use this paper to document and highlight program methodology, evaluation, and key takeaways.

In addition to sustaining new practices offered in faculty development, there are many theories of motivation that can be directly applied to education, although there are several that directly impact faculty development [2]. Motivation is inextricably tied to pedagogy in terms of sustaining or implementing a new practice. In other words, motivation is necessary for institutional change, not only because participants need to be motivated to implement the requested change, but also because motivation will assist with sustaining a new practice [2]. One motivational theory, Vroom's Expectancy Theory [3], discusses the positive correlation between perceived value and motivation. In other words, when more value is placed on a given practice or task, there is a resulting higher motivation to achieve it. This can directly relate to faculty participants and implementing new pedagogy into the classroom. For example, if a faculty member deems a new instructional practice as bringing value to her classroom, then she will be more motivated to work at implementing said 
practice into her classroom. One caveat to this is the idea of cost, or what it will take to implement this new technique successfully [4]. If the perceived cost is low, the motivation will be higher than if the perceived cost is high. In terms of faculty development, if those delivering the development can create a support or design implementation system that faculty believe they can implement successfully and without being overly labor intensive, the idea is that the faculty will respond more favorably to it [5].

While most faculty development programs have a finite timeline of implementation, there are some methods that can be adopted to extend the support or learning for faculty. One such method is the utilization of a Community of Practice (CoP), defined by Wenger et al. [6] as "a unique combination of three elements: a domain of knowledge given by a set of issues; a community of people who care about this domain; and the shared practice in which they are engaged in learning and improving in their domain". Simply put, a CoP allows a group of people with a shared interest to come together and learn from one another. Pimmel and McKenna [7] discuss how CoPs can help sustain a newly introduced practice because members of the group give each other support. Other universities that have researched the impact of CoPs report that the most significant motivators for continuing to attend sessions is the ability to interact with colleagues, to share in learning, and, ultimately, to improve their own teaching practices [8].

\section{Continuing Community of Practice Structure and Implementation}

This paper examines the Continuing Communities of Practice (CCoPs) that ran during the fourth and fifth years of the faculty development program. All of the participants' schedules were tracked to find times that would work for the majority of the participants. Initially, The CCoP was offered as an extension of the previous year's workshops and CoPs for each cohort and used Felder and Brent's Teaching and Learning STEM: A Practical Guide [9]. While the CoP was a mandatory part of the faculty development program, the $\mathrm{CCoPs}$ were voluntary. The two cohorts finished the required $\mathrm{CoP}$ semesters in the Spring of 2017 and results of those sessions and their topics can be reviewed in previous papers [10]. Table 1 provides an overview of the Community of Practice Schedule by grant year. Then, each year is discussed in greater detail.

\section{Table 1}

Community of Practice Overview by Grant Year

\begin{tabular}{|l|l|}
\hline \multicolumn{1}{|c|}{ Year } & \multicolumn{1}{c|}{ Schedule } \\
\hline $\begin{array}{l}\text { Year 1 } \\
\text { Fall 2015 - Spring 2016 }\end{array}$ & Active learning workshops and classroom implementation (cohort 1) \\
\hline $\begin{array}{l}\text { Year 2 } \\
\text { Fall 2016 - Spring 2017 }\end{array}$ & Active learning workshops and classroom implementation (cohort 2) \\
\hline
\end{tabular}




\begin{tabular}{|l|l|}
\hline $\begin{array}{l}\text { Year } 3 \\
\text { Fall } 2017 \text { - Spring 2018 }\end{array}$ & Communities of Practice (Felder and Brent's book) \\
\hline $\begin{array}{l}\text { Year } \mathbf{4} \\
\text { Fall 2018 - Spring 2019 }\end{array}$ & $\begin{array}{l}\text { Continuing Communities of Practice (content expands beyond book } \\
\text { study) }\end{array}$ \\
\hline $\begin{array}{l}\text { Year 5 } \\
\text { Fall 2019 - Spring 2020 }\end{array}$ & Teaching Communities of Practice \\
\hline
\end{tabular}

As noted in Table 1, the CoPs were originally introduced as the second component of the faculty development program. Once the cohort's year expired, the team chose to build out a sustainable continuing CoP to provide ongoing support for faculty working towards implementing active learning strategies into their classes.

\section{Grant Year 4 CCoP}

After reviewing feedback provided during the initial rounds of CoPs and CCoPs, the principal investigator team determined that faculty wanted to continue to receive information that helped them implement active learning and other pedagogical best practices into their classrooms. The topics for the 2018 Fall semester included two sessions on Felder and Brent's Teaching STEM: A Practical Guide and two sessions on migration to the university's new learning management system (LMS). Additionally, the team thought this would be a great opportunity to show faculty how to utilize a LMS to support active learning in the classroom through the use of different edtech apps.

During the Spring 2019 semester, the original format of the sessions was maintained; that is, we still provided a focal topic and allowed for open discussion on that topic or any other topic initiated by faculty participants.. They were held monthly with two options for attendance, and they were each one hour in length. The following topics were selected by the principal investigator team:

1. 3 Ways to Integrate Active Learning into Your Classroom in 10 Minutes or Less!

2. Asking the Right Questions: A Discussion on Building Tests to Improve Student Achievement

3. Psychology-Based Approaches to Improving Student Motivation

4. 5 Features You're Not Using in Canvas (But Should Be).

These topics were selected based on discussion items that arose during the previous semester's CCoPs, as well as themes that still supported student-centered learning in the classroom. One modification for this semester was the inclusion of a truncated PowerPoint presentation that stayed between 5-7 slides. The purpose of the slide set was to help ignite discussion. The participants were reminded that they ultimately chose the direction of the conversation; if the material was not fully covered, that was fine. Most sessions stuck to the topic of the paired slide set, but some sessions veered in the direction of 
faculty discourse on one aspect of the presentation and the full content was not discussed. We felt that this helped provide authenticity and engagement for the participants because it was tailored to their needs and interests, rather than the facilitators.

\section{Grant Year 5 TCP}

As word spread of the CCoPs, and as other grant-funded faculty development programs ended, faculty not initially involved in the original professional development series asked to become a part of the community. To reflect this change and to create an inviting tone, we altered the name of the CCoPs to Teaching Communities of Practice (TCP). We sent introductory emails to the directors of all 9 engineering disciplines (including the two that were not originally involved in the program) to describe the sessions and share the titles of the semester's sessions. We invited them to share this information with their staff and to emphasize the importance of sharing this space to have discussions on evidence-based instructional strategies (EBIS) that would help shift learning to student-centered. From there, we then sent invitations to all participants, including those who had asked to join. This email not only included the same session titles as what was contained in the directors' correspondence, but also an outline of the structure that a typical session followed. We ended the invitation by sharing the schedule; each monthly session had two opportunities to attend. This was done to help faculty fit these times into their schedules. For those members who did not teach at the main campus, a virtual opportunity to join was offered.

The session format also reflected some minor adjustments the team made as a reflection of feedback that we had received at the conclusion of the Spring semester. One of these modifications to the program's original CCoP model was to hold the first TCP session the week before classes started. We were unsure if this would be well attended, but we felt that the topic for the first session was best discussed ahead of the first day of class. We were pleased when this session had one of the highest attendance rates of all CCoP/TCP sessions. The sessions for this semester included the following titles:

1. Setting the Tone/Building Relationships on the First Day of the Engaged Class

2. Do My Students Know What I Want Them to Know? Using a Backward Design Approach to Assessment

3. Getting the Wayward Student Back on Track Using Midterm Formative Feedback and Assessment

4. Motivating Your Students to Finish Strongly: Ending the Semester Successfully.

The 2020 Spring semester followed the same format as the previous semester. The topics included:

1. Adapting Your Syllabus Based on End of Semester Reflections and Feedback

2. Creating Rubrics for Curricular Alignment and Assessment Validity

3. Mastery-Based Grading: Shifting Your Assessment Mindset 


\section{Incorporating Non-Technical Skills into Your Course While Still Prioritizing Content.}

Like the first topic from the Fall semester, we felt that the Spring semester's first topic was best addressed during the week before classes started. One change that we made to the final semester of the TCPs is that we asked faculty participants to share questions they had for students. The questions that were sent back to the team were shared with a panel of students, and we will be using one of the sessions to hold a stakeholder session so that students and faculty can discuss their thoughts on EBIS in the classroom and their impact.

Another component that was continued from the original CoP sessions was the use of faculty "experts"; that is, we had a faculty lead from the PI team at each of the sessions in addition to the pedagogical expert that led the slide set. The purpose of utilizing faculty leads was to preserve the community atmosphere of the session. By having faculty leads guide the discussion, participants were still able to have authentic and organic conversation about their practice without feeling like an outsider was providing them with information only; it was less like a workshop and more of a roundtable. The pedagogy specialist, someone with experience not only with teaching, but also with instructional design and EBIS, served as a facilitator of the selected topic's information, but was not the focal point of the session. Ideas were able to free-flow among colleagues without corrective guidance. With that in mind, there were times when the specialist was asked to clarify a concept or to further explain it, but the specialist was not critical of any practice discussed within the sessions. This prevented any feeling of judgment or criticism within the CoP sessions.

\section{Evaluation and Results}

\section{Attendance}

The CCoPs and subsequent TCPs were examined in several ways. Attendance was tracked by head counts, but faculty were not required to sign in when they attended. The PI team decided that these sessions needed to grow and sustain themselves intrinsically, and having required sign-ins or other modes of explicit attendance taking were not conducive to that atmosphere. Therefore, based on informal headcounts and requests for slide sets, the average attendance rate for each monthly session over years 4 and 5 of the grant ran between 15 and 30 participants, or between 18 and 37 percent of the JTFD participants. This average increased from year 4 to year 5 , with participation starting at an average of 25 for year 5, compared to an overall average of 20 for year 4 . It is important to note, however, that the last year of the TCPs was the year in which the participant invite list grew from 82 to 122 to include faculty outside of the grant who requested to join the sessions. While most of the JTFD participants continued to attend as their schedules allowed, we acknowledge that the increase of average attendance was largely due to the added faculty. What we did see, however, was that JFTD faculty who had not previously attended earlier years began participating. 


\section{Survey}

As aforementioned, the original CoPs were evaluated with self-reporting surveys that measured faculty perception of value of the sessions, but the CCoPs were not given surveys at the conclusion of each session. At the end of the first year of the CCoPs, participants present at the last session were asked to complete a voluntary survey as a way to collect feedback about the session structure and future considerations. The survey consisted of four questions that used a five-point Likert scale from strongly disagree to strongly agree. Following those questions were three open-ended questions:

1. Please provide feedback on the structure of the TCPs. Consider things like the length of the slide set, the use of outside speakers, and the length of the sessions themselves. What did you like, and what suggestions do you have for next year?

2. What has been the largest contributor to the degree of your participation this year? Do you expect to change in the future?

3. How have your teaching beliefs changed as a result of the TCPs, and how have those changes impacted your classroom practice?

Table 2 shows the questions that used the Likert scale with the average response, and Table 3 includes examples of feedback from the open-ended questions.

Table 2

Average Response in Self-Reporting Feedback Survey (out of 5)

\begin{tabular}{|l|c|}
\hline \multicolumn{1}{|c|}{ Likert Scale Question } & $\begin{array}{c}\text { Average Response } \\
(\mathbf{n = 1 0})\end{array}$ \\
\hline $\begin{array}{l}\text { The topics discussed in these sessions were relevant and helpful } \\
\text { to my teaching practice. }\end{array}$ & 4.8 \\
\hline $\begin{array}{l}\text { The topics discussed provided me with new ideas for } \\
\text { implementation and/or reaffirmed strategies I am currently } \\
\text { implementing. }\end{array}$ & 4.8 \\
\hline $\begin{array}{l}\text { The discussions and community-building with other faculty is } \\
\text { valuable. }\end{array}$ & 4.8 \\
\hline $\begin{array}{l}\text { I would recommend participation in the TCP program to other } \\
\text { colleagues. }\end{array}$ & 4.8 \\
\hline
\end{tabular}

Table 3 shows the open-ended questions asked on the survey and includes the responses provided. The responses were paraphrased for length and the number of respondents who echoed a response is listed in parentheses after the response. 


\section{Table 3}

TCP Feedback Survey Statements and Sample Responses

\begin{tabular}{|c|c|}
\hline Question & Responses (edited for length) \\
\hline $\begin{array}{l}\text { Please provide feedback on the } \\
\text { structure of the TCPs. Consider things } \\
\text { like the length of the slide set, the use } \\
\text { of outside speakers, and the length of } \\
\text { the sessions themselves. What did you } \\
\text { like, and what suggestions do you } \\
\text { have for next year? }\end{array}$ & $\begin{array}{l}\text { - Varied topics were appreciated } \\
\text { - More time to discuss specific issues } \\
\text { - Great personal investment - felt welcome } \\
\text { - Continue providing follow-up to sessions } \\
\text { - Continue on in a similar way } \\
\text { - Liked information provided as well as slide set } \\
\text { length and session length } \\
\text { - Offer longer session to share out program goals } \\
\text { - It was good }\end{array}$ \\
\hline $\begin{array}{l}\text { What has been the largest contributor } \\
\text { to the degree of your participation this } \\
\text { year? Do you expect to change in the } \\
\text { future? }\end{array}$ & $\begin{array}{l}\text { - Conducive/non-conducive schedule (4) } \\
\text { - Multiple session choices } \\
\text { - TCP helps us scale without compromising quality } \\
\text { - Interesting and focused themes } \\
\text { - Sharing ideas with my colleagues }\end{array}$ \\
\hline $\begin{array}{l}\text { How have your teaching beliefs } \\
\text { changed as a result of the TCPs, and } \\
\text { how have those changes impacted } \\
\text { your classroom practice? }\end{array}$ & $\begin{array}{l}\text { - You have helped me think about how to change } \\
\text { - Ky practice } \\
\text { - We need more focus on creativity } \\
\text { - Makes things more organized and responsive to } \\
\text { - students } \\
\text { - Haven't changed (2) } \\
\text { - It has been nice to meet with colleagues }\end{array}$ \\
\hline
\end{tabular}

There were ten responses from those who attended the final CCoP session at the end of year 4. Out of those responses, $100 \%$ reported that they found continued value in attending the CCoP sessions (score 4.78 out of 5). Similarly, all respondents reported learning new ideas that they could implement in the classroom (score 4.78 out of 5). With regard to the open-ended questions, $80 \%$ of the respondents reported that their classroom practices had changed. Additionally, 50\% stated that the best contributor to their regular attendance was the schedule and the ability to choose between two sessions each month. Overall, the comment illustrated that all who reported found value in these sessions. 


\section{Discussion}

Overall, the team has noted that the number of faculty who participate in the communities of practice has grown slightly. The team also realizes that extending a faculty development program and its innovations takes time [11]. While this could be explained by the added number of faculty invitations, overall, we feel that several program features have continued to the sustained participation. One, the team has strived to include current and relevant pedagogical topics that not only align with the overarching goal of infusing active learning strategies into the engineering classroom, but we also consciously chose topics that were able to be differentiated. In other words, we strove to scaffold information to create a holistic approach to addressing the different points in a faculty member's career. The topics we have discussed in our sessions are relevant to new faculty and veteran faculty because they fall along the continuum that is active learning.

Another factor that aided in our ability to sustain our numbers was providing two options for attendance. While it is impossible to accommodate all faculty, we prioritized those who were regular attendees so that they felt we valued their time and participation. We also held each session option in different locations to help reach more faculty; we chose central locations based on participants' schedules so that their commute to each session was not an extra hindrance.

\section{Conclusions}

Building a sustainable $\mathrm{CoP}$ is no easy feat. Faculty are busy with classes and increasing class sizes, and prioritizing pedagogy at a highly competitive research university comes with its own set of obstacles. What we found was the most helpful was taking the time to look at each participant's schedule and build out options for monthly CCoPs/TCPs that gave preference to those who regularly attended. Additionally, choosing central locations to reduce the faculty participants' commute also helped lower the perceived cost of attending.

Other areas that helped with sustaining our faculty development was the use of faculty leads in addition to the pedagogy specialist. The faculty leads served as the faces of the CCoP/TCPs and also acted as promoters. Choosing veteran faculty as faculty leads ensured that most of the participants knew them and helped motivate them to attend. Also reaching out to program directors to share our information and invite their faculty to attend helps motivate faculty or validate the relevance of our sessions to their practice.

We chose monthly sessions at an hour a piece for several reasons. For one, there are currently several large-funded grants in which many of our faculty are involved. Pragmatically speaking, we knew that over scheduling would result in poorer attendance; being mindful of their time and being proactive with scheduling helped us to circumvent that to a degree. 
While we would have liked to see a higher percentage of attendance at each session, we understand that obstacles such as overlapping professional development and prioritizing research can limit attendance. Despite not achieving a higher average attendance, we were pleased that faculty reported finding value in the sessions, not only with providing a space for faculty to come together as a community, but also with providing new practices they could implement into their classrooms. Similarly, we were extremely pleased that all of the faculty who have participated in these sessions have found value in coming together as a community and sharing ideas on how they shift their teaching from teacher-centered to student-centered learning. Overall, sustaining this CCoP/TCP allowed the principal investigator team to extend the faculty development program they originally implemented nearly five years ago. As these continue, we look to see an increased use of active learning taking place in engineering classrooms at the university. A community of practice can be an excellent way to establish a regular meeting place for faculty from multiple disciplines to come together and share their teaching experience. Ultimately, infusing the aforementioned characteristics into a CoP can help sustain a new instructional practice once the initial faculty development program is over. Additionally, this can be easily adapted to any program as it scales well and can be used to address any type of faculty development.

Acknowledgement: The authors gratefully acknowledge the support of this work by the National Science Foundation under Grant No. 1524527. 


\section{References}

[1] Layne, J., J. Froyd, N. Simpson, R. Caso, and P. Merton. (2004). Understanding and improving faculty professional development in teaching; Proc. 34th FIE conf. Available at http://fieconference.org/fie2004/papers/1420.pdf

[2] Tollefson, N. (2000). Classroom applications of cognitive theories of motivation. Educational Psychology Review, 12: 63. https://doi.org/10.1023/A:1009085017100

[3] Vroom, V. H. (1964). Work and motivation. New York: Wiley.

[4] Author (2018)

[5] Author (2017)

[6] Wenger, E., McDermott, R., and Snyder, W. (2002). Cultivating Communities of Practice. Cambridge, MA: Harvard Business School Press.

[7] Pimmel, R., and McKenna, A. (2014). Sponsored Session M464A, Faculty development using virtual communities of practice. 2014 ASEE Annual Conference Proceedings.

[8] Vescio, V., Ross, D., \&amp; Adams, A. (2008). A review of research on the impact of professional learning communities on teaching practice and student learning. Teaching and Teacher Education, 24, 80-91.

[9] Felder, R. M., \& Brent, R. (2016). Teaching and learning STEM . San Francisco, CA: John Wiley \& Sons, Inc.

[10] Author (2018)

[11] Coto, M. and L. Dirckinck-Holmfeld (2008). Facilitating communities of practice in teacher professional development; Proc. Sixth Internat. Conf. Networked Learning. Available at:

www.networkedlearningconference.org.uk/past/nlc2008/abstracts/PDFs/Coto 54-60.pdf 